\title{
Computational modelling studies for high temperature monazite systems
}

\author{
L Motsomone*a, RG Diale ${ }^{\mathrm{a}}$, PE Ngoepe ${ }^{\mathrm{a}}$, R Koen, ${ }^{\mathrm{b}}$ HR Chauke ${ }^{\mathrm{a}}$ \\ aMaterials Modelling Centre, University of Limpopo, Private Bag X 1106, Sovenga, 0727, South Africa \\ ${ }^{b}$ The South African Nuclear Energy Corporation Ltd. (Necsa), P.O. Box 582, Pretoria, 0001, South Africa \\ Email:Imotsomone@gmail.com*, ramogohlo.diale@ul.ac.za, phuti.ngoepe@ul.ac.za, renier.Koen@necsa.co.za, hasani.chauke@ul.ac.za
}

\begin{abstract}
Monazite is widely considered as a potential source of fissile feedstock for nuclear power generation, as it generally contains significant quantity of thorium (Th), uranium (U) and rare earth elements (REEs) within the mineral ore structure. Currently, a new process of high-temperature cracking of monazite is under development to improve the liberation of these cations from the robust monazite lattice. The current process for extraction of the REEs from the mineral involves complicated processes which makes use of harsh chemicals. These process therefore has significant scope for optimisation. With this in mind, the stability of monazite systems, $\mathrm{t}^{-\mathrm{CeSiO}} \mathrm{S}_{4}$ and $\mathrm{m}-\mathrm{LaSiO}_{4}$ was investigated using first-principle calculation employing density functional theory (DFT) to gain a better understanding of the inherent molecular structures and the influence of temperature on conformation. The calculated lattice parameters for the model of $\mathrm{t}-\mathrm{CeSiO}_{4}$ were found to be in good agreement with the experimental values (within $3 \%$ ) and deemed a sufficient $\mathrm{m}-\mathrm{LaSiO}{ }_{4}$ of the system to be exposed to simulated reaction conditions. The elastic properties suggested that $\mathrm{t}-\mathrm{CeSiO}_{4}$ is the more stable structure compared to $\mathrm{m}_{-} \mathrm{LaSiO}_{4}$ structure at $0 \mathrm{~K}$. Semi-empirical embedded atom method interatomic potentials incorporated in the LAMMPS code were also employed to investigate the lattice expansion of $\mathrm{t}_{-} \mathrm{CeSiO}_{4}$ at high temperatures. It was found that calculated $a$ and $b$ lattice parameters expand with a linear ratio to a temperature of $2200 \mathrm{~K}$ whereas the $c$ parameter was found to contract in the same temperature range. The findings provided an in depth understanding of the monazite molecular structure change at higher temperatures that may be helpful in plasma cracking optimisation experimental methodologies.
\end{abstract}

Keywords: Monazite, LAMMPS code, Lattice expansion, Stability

\section{Introduction}

Monazite [Ce, $\mathrm{La}, \mathrm{Nd}$, Th $\left.\left(\mathrm{PO}_{4}, \mathrm{SiO}_{4}\right)\right]$ is an important mineral in the mining industry and contains non-trivial amounts of rare earth elements (REE), thorium (Th) and uranium (U) (Richter et al., 2019). These components (REE, Th, and U) are exceptionally significant and find application in numerous areas of modern technology. The phosphate mineral exists in three common forms, monazite-(Ce), monazite-(La) and monazite-(Nd) (Santos et al., 2018) and is known to be chemically very stable and highly inert (Kemp and Cilliers, 2016). It has an extremely broad range of chemical compositions reflecting ore formation in a wide variety of rock types under variable conditions. These conformations form under differing pressure and temperature environment in sedimentary, metamorphic and igneous rocks (Hoshino et al., 2016). The constituent elements of monazite can be used in a wide variety of applications including catalysis, metallurgy, glass/ polishing and magnetic sector (Catlos et al., 2008).

It has been well-documented that the use of conventional chemical processes to extract the REEs, thorium and uranium from monazite has developed into a highly complicated and costly exercise (Kemp and Cilliers, 2016). Hence, computational modelling offers an opportunity to simulate these labour intensive experiments in a more effective and less costly manner. Accordingly, we used representative models and simulated reaction conditions to assist in to understanding how we could best extract these REEs by gaining insight into structural conformations at elevated temperatures. In this paper, the high temperature cracking of monazite systems, using a Large-scale Atomic/Molecular Massively Parallel Simulator (LAMMPS) to investigate the lattice expansion at high temperatures was evaluated. In addition, we also calculated the heats of formation to predict thermodynamic stability, as well as the elastic constants to predict the mechanical stability, ductility and brittleness of the systems at zero temperature. More importantly, it was established that the monazite mineral showed improved strength at a temperature below the melting point.

\section{Methodology}

The required calculations were performed using the Vienna ab initio simulation package (VASP) code (Kresse and Hafner, 1993), based on the density functional theory (DFT). The exchangecorrelation interaction was evaluated with the generalized gradient approximation (GGA) (Kohn and Sham, 1965) of Perdew-BurkeErnzerhof (PBE) (Perdew et al., 1996). A plane wave cutoff energy of $500 \mathrm{eV}$ and k-point mesh of $12 \times 12 \times 11$ for $\mathrm{t}_{-} \mathrm{CeSiO}_{4}$ and $12 \times 10 \times 11$ for $\mathrm{m}-\mathrm{LaSiO}_{4}$, respectively, were used to converge the total energy of the structures. Optimization of structural parameters was obtained by minimization of forces and stress tensors. The elastic constants were calculated for a small strain of 0.003 . The semi-empirical embedded atom method (EAM) (Daw and Baskes, 1984) incorporated in LAMMPS code (Plimpton, 1995) was employed to investigate the lattice expansion of $\mathrm{CeSiO}_{4}$ at high 
temperatures. An $8 \times 8 \times 8$ supercell of $\mathrm{CeSiO}_{4}$ containing 1024 atoms was used. The temperature was varied from 400 to $2200 \mathrm{~K}$. The isobaric-isothermal NPT ensemble was chosen with 100 ps simulation time and timestep of $2 \mathrm{fs}$

\section{Results and Discussion}

\subsection{Structures and thermodynamic properties}

Table 1 lists the calculated and experimental lattice parameters, as well as the heats of formation for the optimised structures of (t-CeSiO 4 and $\mathrm{m}-\mathrm{LaSiO}_{4}$ ). The results of equilibrium lattice parameters were in good agreement with available experimental values (to within 5 \%) (Kamal and Francesca, 2019).

The thermodynamic stability of these systems can be deduced from the heats of formation $\left(\Delta H_{f}\right)$ calculations. In order for a structure to be confirmed as the most stable configuration, the $\Delta H_{f}$ must have the lowest possible value (generally $\Delta H_{f}<0$ ), where any value larger than this, implies instability.

The following expression estimates the heats of formation $\left(\Delta H_{f}\right)$ :

$\Delta \mathrm{H}_{\mathrm{f}}=E_{C}-\sum_{i} x_{i} E_{i}$

where $E_{C}$ is the calculated total energy of the compound and $E_{i}$ is the calculated total energy of each element in the compound.

When directly comparing the $\Delta H_{f}$ values of the candidate compounds within the scope of this study, $\mathrm{t}-\mathrm{CeSiO}_{4}$ was found to be more stable $(-2.0740 \mathrm{eV} /$ atom $)$ while $\mathrm{m}-\mathrm{LaSiO}_{4}(-1.9500 \mathrm{eV} /$ atom) highlighted a less stable structure configuration, as noted in Table 1.

\subsection{Elastic properties at $0 \mathrm{~K}$}

The calculation of elastic constants is essential for determining and quantifying the macroscopic mechanical properties that define the mechanical inherent stability of compounds. Note that the stability criterion for the elastic constants must be satisfied in order for the structure to be defined as stable.

The mechanical stability condition for tetragonal system (Mehl and Klein, 1994) is as follows:

$\mathrm{c}_{44}>0, \mathrm{c}_{66}>0, \mathrm{c}_{11}>0, \mathrm{c}_{33}>0, \mathrm{c}_{11}-\mathrm{c}_{12}>0,\left(\mathrm{c}_{11}+\mathrm{c}_{33}-2 \mathrm{c}_{13}\right)>0,2\left(\mathrm{c}_{11}+\mathrm{c}_{3}+2 \mathrm{c}_{12}\right.$ $\left.+4 \mathrm{c}_{13}\right)>0$

For monoclinic crystal stability condition, outlined (Bao et al., 2010) is as follows:

$\mathrm{c}_{11}>0, \mathrm{c}_{22}>0, \mathrm{c}_{33}>0, \mathrm{c}_{44}>0, \mathrm{c}_{55}>0, \mathrm{c}_{66}>0,\left(\mathrm{c}_{22}+\mathrm{c}_{33}-2 \mathrm{c}_{23}\right)>0$,

Table 2 show the elastic constants and elastic shear moduli of the candidate monazite structures. Note that $\mathrm{m}-\mathrm{LaSiO}_{4}$ is deemed to be mechanically unstable since it notes negative values of $c_{25}$ and $\mathrm{c}_{46}$, implying that the monoclinic stability criteria are not satisfied. In the case of $\mathrm{t}-\mathrm{CeSiO}_{4}$, the tetragonal stability criteria are satisfied and it is deemed the more stable structure as it has the highest $C^{\prime}$.

The calculated bulk, shear, and young modulus for the monazite systems are shown in Table 3. Elastic moduli is only shown for Voigt approximation, with the calculated values being very close to the experimental results for $\mathrm{t}_{-} \mathrm{CeSiO}_{4}( \pm 3 \%$ error)(Kamal et al., 2019). It is seen that the $\mathrm{t}-\mathrm{CeSO}_{4}$ structure has large value of bulk, shear and young's modulus indicating that the compound is hard, with a high degree of stiffness and is not easily compressed.

Furthermore, we calculated the ratio of bulk modulus to shear modulus $(B / G)$ to investigate the extent of fracture range in these structures. Pugh (1954) proposed that materials are considered to be ductile if the value of Pugh's criterion $(B / G)>1.75$. It is observed that calculated $\mathrm{B} / \mathrm{G}$ ratio is greater than 1.75 for both the $\mathrm{t}-\mathrm{CeSiO}_{4}$ and $\mathrm{m}-\mathrm{LaSiO}_{4}$ structures, signifying ductile behaviour. In order to substantiate this even further, the Poisson ratio (o) was calculated and considered as ductile if $(\sigma)>0.26$ (Frantsevich and Voronov, 1983). When considering the information in Table 3 it is clearly seen that the Poisson's ratio for both compounds is $>0.26$, further confirming the ductile nature of $\mathrm{t}-\mathrm{CeSiO}_{4}$ and $\mathrm{m}-\mathrm{LaSiO}_{4}$.

Table 2: Elastic constants $\left(\mathrm{C}_{\mathrm{ij}}\right)$, and elastic shear modulus $\left(C^{\prime}\right)$ of $\mathrm{t}-\mathrm{CeSiO}_{4}$ and $\mathrm{m}-\mathrm{LaSiO}_{4}$ structures at $0 \mathrm{~K}$

\begin{tabular}{ccc}
\hline Elastic Constant $\mathbf{C}_{\mathbf{i j}}$ (Gpa) & $\mathbf{t}_{\mathbf{C}} \mathbf{C e S i O}_{\mathbf{4}}$ & $\mathbf{\text { m-LaSiO }}$ \\
\hline $\mathrm{c}_{11}$ & 256.89 & 187.84 \\
$\mathrm{c}_{12}$ & 41.42 & 61.92 \\
$\mathrm{c}_{13}$ & 107.35 & 61.73 \\
$\mathrm{c}_{15}$ & - & 5.50 \\
$\mathrm{c}_{22}$ & - & 197.65 \\
$\mathrm{c}_{23}$ & - & 85.90 \\
$\mathrm{c}_{25}$ & - & -5.77 \\
$\mathrm{c}_{33}$ & 336.36 & 172.53 \\
$\mathrm{c}_{35}$ & - & 5.29 \\
$\mathrm{c}_{44}$ & 61.47 & 42.35 \\
$\mathrm{c}_{46}$ & - & -6.76 \\
$\mathrm{c}_{55}$ & - & 33.80 \\
$\mathrm{c}_{66}$ & 26.22 & 32.94 \\
$C^{\prime}$ & 215.47 & 62.65 \\
\hline
\end{tabular}

\subsection{Lattice expansion}

In an attempt to gain a better understanding of the effects of temperature manipulations on the more stable $\mathrm{t}-\mathrm{CeSiO}_{4}$ structure, a theoretical calculation of lattice expansion effects with changing

Table 1: Space group, Pearson symbol lattice parameters and heats of formation for $\mathrm{CeSiO}_{4}$ and $\mathrm{LaSiO}_{4}$ structures

\begin{tabular}{lcccccc}
\hline Structure & Pearson symbol & Space group & a $(\AA)$ & b $(\AA)$ & c $(\AA)$ & $\Delta \mathbf{H}_{\mathbf{f}}(\mathbf{e V} \backslash \mathbf{a t o m})$ \\
\hline $\mathrm{CeSiO}_{4}$ (this study) & t124 & $141 / \mathrm{AMDZ}$ & 6.9564 & 6.9564 & 6.1953 & -2.0740 \\
& & & & & \\
$\mathrm{CeSiO}_{4}$ (Kamal et al., 2019) & tl24 & 141/AMDZ & 7.0100 & 7.0100 & 6.9100 & \\
$\mathrm{LaSiO}_{4}$ & $\mathrm{mP24}$ & P2_1/c & 6.4700 & 7.0700 & 8.2399 & -1.9500 \\
\hline
\end{tabular}


Table 3: Calculated bulk (B), shear (G) and Young's (E) moduli values as well as the Poisson and $\mathrm{Pugh}$ ratios of $\mathrm{t}-\mathrm{CeSiO}_{4}$ and $\mathrm{m}-\mathrm{LaSiO}_{4}$ at $0 \mathrm{~K}$.

\begin{tabular}{llll}
\hline $\begin{array}{l}\text { Elastic modulus } \\
\text { (GPa) }\end{array}$ & $\begin{array}{lll}\text { t-CeSiO } \\
\end{array}$ & This study & $\begin{array}{l}\text { Exp. } \\
\text { (Kamal } \text { et al., } \\
\text { 2019) }\end{array}$ \\
\hline $\mathrm{B}^{\mathrm{v}}$ & 151.38 & 150.67 & 108.57 \\
$\mathrm{G}^{\mathrm{v}}$ & 69.43 & 64.60 & 46.25 \\
\hline $\mathrm{E}^{\mathrm{v}}$ & 180.68 & 169.57 & 121.50 \\
\hline Poisson's ratio & 0.30 & & 0.31 \\
\hline Pugh's ratio (B/G) & 2.18 & & 2.35 \\
\hline
\end{tabular}

temperature was undertaken, with results illustrated in Figure 1. Figure 1 (a) shows that $a$ and $b$ lattice parameters increase linearly while c lattice parameter decreases (similarly linear) as the temperature is increased. This behaviour suggests that the structure $\mathrm{t}-\mathrm{CeSiO}_{4}$ is constructing along the $c$ direction. An increase in $b$ parameter behaviour shows that it expands linearly to the temperature of $\pm 2250 \mathrm{~K}$ after which elongation is halted, suggesting that there is no further expansion above the melting point $(2273 \mathrm{~K})$.

Note that lattice ratios $(a / b, c / a$ and $c / b)$ as shown in Figure 1 (b) are applied to determine the phase transformation temperature as

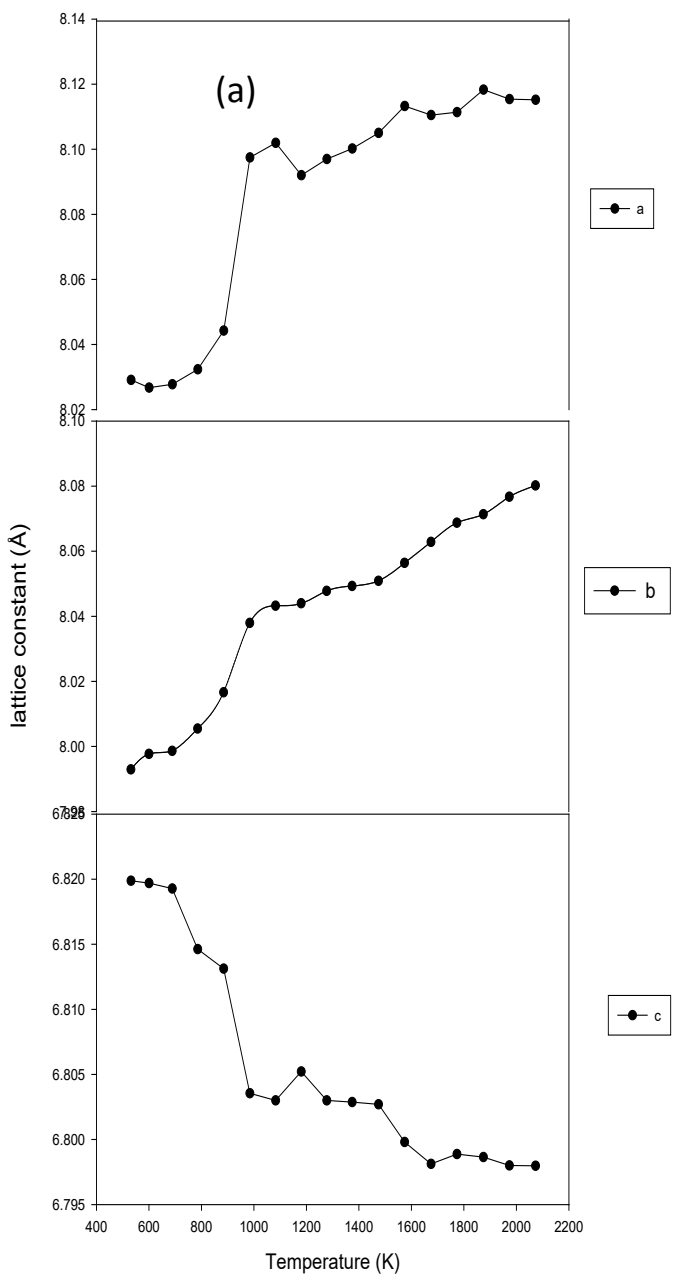

a function of significant lattice parameter change. It is noted that the $a / b$ ratio is approximately linear to the temperature of 2250 $\mathrm{K}$, before a deviation is noted. This inflection which corresponds to the experimental melting point temperature of $\mathrm{t}-\mathrm{CeSiO}_{4}$ (2273 K) (Hikichi et al., 1997) and is not ascribed to a structural transformational rearrangement but rather an artifact of melting. The $c / a$ and $c / b$ ratios display a similar linearity with ratios for both until the system approaches melting point and melting deviations are observed. Note that there is no temperature induced transformational phase changed observed in the $\mathrm{t}-\mathrm{CeSiO}_{4}$ structure.

\section{Conclusion}

The first-principle calculations were used to study the equilibrium lattice parameters, heats of formation and elastic properties of $\mathrm{t}-\mathrm{CeSiO}_{4}$ and $\mathrm{m}-\mathrm{LaSiO}_{4}$. The calculated lattice parameters for $\mathrm{t}-\mathrm{CeSiO}_{4}$ were found to be in good agreement with experimental values (within $3 \%$ error) which implies a sufficient $\mathrm{m}-\mathrm{LaSiO}_{4}$ of the model system. From calculated elastic constants, it was found that the tetragonal $\mathrm{CeSiO}_{4}$ structure is more stable on a macroscale) than the monoclinic $\mathrm{m}-\mathrm{LaSiO}_{4}$ analogue at $0 \mathrm{~K}$, because it has a higher elastic shear modulus (C').

In order to compare and evaluate the hardness and ductility of the candidate structures, bulk, shear and Young's moduli and the Poisson ratio were of each candidate compound was calculated. It was noted that these theoretical values were in good agreement

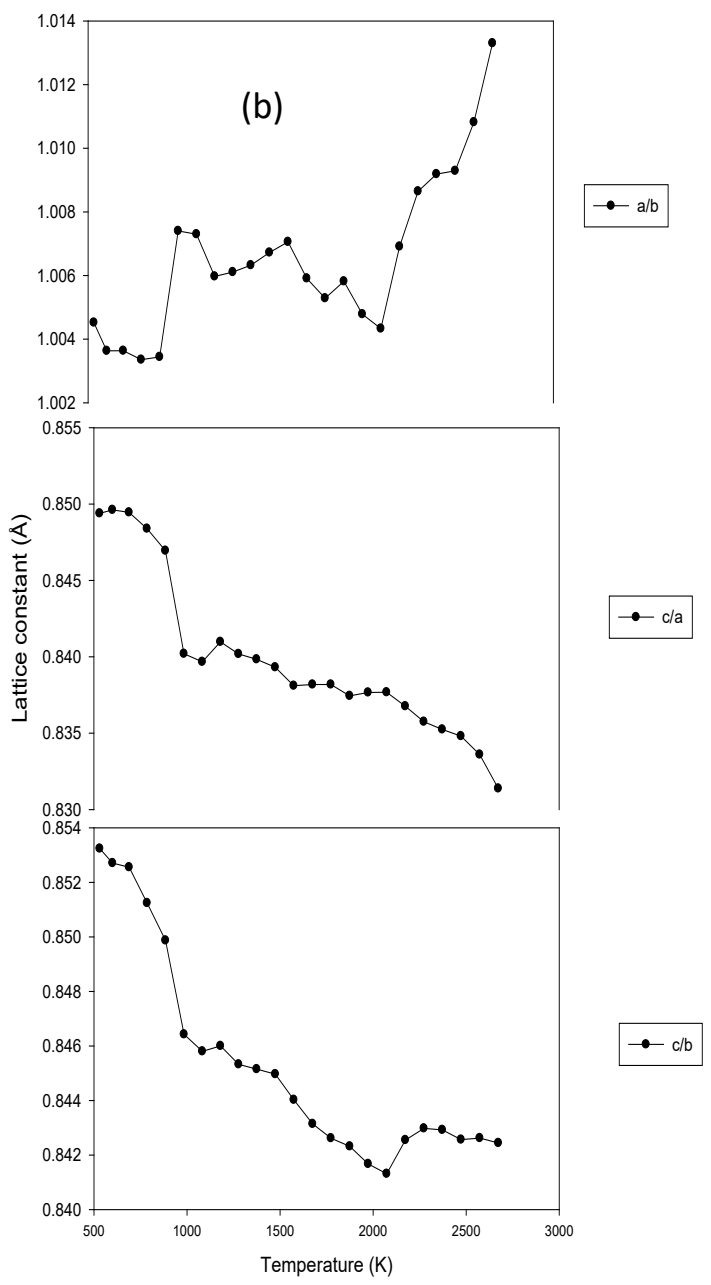

Figure 1: (a) The effect of temperature on $\mathrm{a}, \mathrm{b}$ and $\mathrm{c}$ lattice (b) on a/b, c/a and c/b ratio parameters of t- $\mathrm{CeSiO}_{4}$ 
with those noted from experimental results in literature (e.g within $5 \%$ error for $\mathrm{t}-\mathrm{CeSiO}_{4}$ ). From these results in could be theoretically determined that both $\mathrm{t}-\mathrm{CeSiO}_{4}$ and $\mathrm{m}-\mathrm{LaSiO}_{4}$ are considered ductile in nature, substantiating what is observed with real-world macroscopic samples.

The high temperature phase evaluation of monazite was performed using LAMMPS code. It was shown that the $\mathrm{t}-\mathrm{CeSiO}_{4}$ structure expand along $a$ and $b$ lattice parameters and contracts along the $c$ lattice parameter with an increase in temperature implying a structure that is constructed along the $c$ direction. In addition, the lattice ratios $a / b, c / a$ and $c / b$ were compared in an attempt to determine if the structure undergoes a crystallographic phase transition before melting. The linearity of these ratios below a temperature of $2200 \mathrm{~K}$ would suggest that the monoclinic conformation remains intact until melting. The trends in these properties show that, when they are modified in a specific manner (for example, by high-temperature cracking), better results can be obtained regarding the liberation of cations from the material.

\section{Acknowledgments}

The work was carried at the Materials Modelling Centre, University of Limpopo and the centre for High Performance Computing (CHPC). The authors would like to acknowledge the financial support of the Department of Science and Innovation (DSI), through the Nuclear Materials Development Network (at Necsa) of the Advanced Materials Initiative (AMI). The support of South African Research Chair initiative of Department of Science and Innovations is highly appreciated.

\section{References}

1. Bao G, Duan D, Zhou D, Jin X, Liu B and Cui TJ. (2010). New High-Pressure Polar Phase of Crystalline Bromoform: A
First-Principles Study. Journal of Physical Chemistry B, 114 13933-13939.

2. Catlos EJ, Baker CB, Çemen I and Ozerdem C . (2008). Whole-rock major element influences on monazite growth: examples from igneous and metamorphic rocks in the Menderes Massif, western Turkey. Mineralogia, 39, 7-30.

3. Kemp D and Cilliers AC. (2016). High-temperature thermal plasma treatment of monazite followed by aqueous digestion. Journal of the Southern African Institute of Mining and Metallurgy, 10, 901-906.

4. Daw MS and Baskes MI . (1984). Embedded-atom method: Derivation and application to impurities, surfaces, and other defects in metals. Physical Review B, 29, 6443-6453.

5. Frantsevich IN and Voronov SA. (1983). Elastic Constants and Elastic Moduli of Metals and Insulators. Naukova Dumka, Kiev, 60-180.

6. Hikichi Y Ota T and Hattori T. (1997). Thermal, mechanical and chemical properties of sintered monazite. Mineralogical Journal, 19, 123-130.

7. Hoshino M, Sanematsu K and Watanabe Y. (2016). Chapter 279-REE mineralogy and resources. Handbook on the physics and chemistry of rare earth, 49, 129-291.

8. Kamal C and Francesca T. (2019). Convergence and machine learning predictions of Monkhorst-Pack k-points and plane-wave cut-off in high-throughput DFT calculations. computational material science, 161, 300-308.

9. Kohn W and Sham LJ. (1965). Self-Consistent Equations Including Exchange and Correlation Effects. Physical Review, 140, 1133-1138.

10. Kresse G and Hafner J. (1993). Ab initio molecular dynamics for liquid metals. Physical Review B, 47, 558.

11. Mehl MJ and Klein BM. (1994). In Intermetallic Compounds Principles and Practice. J. W. a. R. Fleischer, Ed., J. Wiley and Sons Ltd, 1, 195-210.

12. Perdew JP, Burke K and Ernzerhof M. (1996). Generalized Gradient Approximation Made Simple. Physical Review Letters, 77, 3865.

13. Plimpton S . (1995). Fast Parallel Algorithms for Short-Range Molecular Dynamics. Journal of Computational Physics, 117, 1-19.

14. Pugh S. (1954). Relations Between the Elastic Moduli and the Plastic Properties of Polycrystalline Pure Metals. Philosophical Magazine, 45 823-843.

15. Richter M,Oliver N, Thomas Z and Regina M. (2019). Assessment of Five Monazite Reference Materials for $\mathrm{U}-\mathrm{Th} / \mathrm{Pb}$ Dating Using Laser-Ablation ICP-MS. Geosciences, 9, 391.

16. Santos JJA, Conceição H, Leandro MVS, Rosa MLS. (2018) Formation of monazite-(Ce, La) by fluid-apatite interaction: the Floresta Azul Alkaline Complex, Bahia, Brazil. Brazilian Journal of Geology, 48, 721-733. 